\title{
Fibromyalgia and the therapeutic relationship: Where uncertainty meets attitude
}

\author{
Sean M Hayes PsyD ${ }^{1}$, Genevieve C Myhal PhD ${ }^{1}$, John F Thornton MD FRCPC ${ }^{2}$, Monique Camerlain MD FRCPC 3 , \\ Cynthia Jamison $\mathrm{MBA}^{4}$, Kayla N Cytryn PhD RN ${ }^{1}$, Suzanne Murray ${ }^{1}$
}

SM Hayes, GC Myhal, JF Thornton, et al. Fibromyalgia and the therapeutic relationship: Where uncertainty meets attitude. Pain Res Manage 2010;15(6):385-391.

BACKGROUND: Fibromyalgia remains underdiagnosed and suboptimally treated even though it affects an estimated $3.3 \%$ of Canadians. The present study examines knowledge and attitudinal challenges affecting optimal care.

METHODS: A mixed-methods approach was employed. Discussion groups, semistructured interviews and a quantitative online survey (fivepoint scale) were conducted (June 2007 to January 2008). Participants included 189 general practitioners (GPs) and 139 specialists (anesthesiologists, neurologists, physiatrists, psychiatrists and rheumatologists) distributed across Canada. Participants included 18 patients to enrich the scope of the findings.

RESULTS: GPs reported insufficient knowledge and skill in diagnosing fibromyalgia, with not all believing it to be a diagnosable condition (mean $3.74 / 5)$. Twenty-three per cent of GPs and $12 \%$ of specialists characterized fibromyalgia patients as malingerers. They further reported a lack of knowledge and skill in treating fibromyalgia (mean 2.73/5), including the pain, sleep disorders and mood disorders related to the condition (mean 3.32/5). Specialists shared these challenges, although to a lesser degree - "We are not trained to treat distress and suffering" (Specialist). Attitudinal issues centred around frustration (mean 3.91/5) and negative profiling of fibromyalgia patients (mean 3.06/5 and 1.99/5).

CONCLUSIONS: Findings revealed the presence of GP attitudinal and confidence challenges in caring for fibromyalgia patients. As care of fibromyalgia patients moves to general practices, these fundamental competencies must be addressed to assure that all patients receive the quality of care necessary to manage their disease and to empower physicians to be more professionally effective. As stated by one patient, "Why are we being penalized for having this disability?"

Key Words: Doctor-patient relationship; Fibromyalgia; Mixed-method research; Pain; Patient profiling; Qualitative research

E fective patient-physician therapeutic relationships present challenges to patients and physicians in caring for patients with fibromyalgia, an often underdiagnosed, undertreated (1) and misunderstood disorder (2). Fibromyalgia affects an estimated $3.3 \%$ of Canadians (3), of which an estimated $1.1 \%$ are diagnosed (4). The female-to-male ratio is estimated to be 3.8:1 (3). However, in spite of American College of Rheumatology (ACR) (2) and Canadian Consensus (5) guidelines intended to clarify fibromyalgia, clear parameters to guide diagnosis and monitoring remain lacking.

Fibromyalgia symptoms and causes are not sufficiently clear to guide diagnosis and monitoring. Patients with fibromyalgia

\section{La fibromyalgie et la relation thérapeutique : Une rencontre entre l'incertitude et l'attitude}

HISTORIQUE : La fibromyalgie demeure sous-diagnostiquée et son
traitement est sous-optimal, même si elle touche une proportion estimative
de $3,3 \%$ de Canadiens. La présente étude porte sur les connaissances et les
obstacles liés aux attitudes ayant une incidence sur des soins optimaux.
MÉTHODOLOGIE : Les chercheurs ont privilégié une démarche mixte.
Ils ont organisé des groupes de discussions, des entrevues semi-structurées
et une enquête quantitative électronique (échelle de cinq points) entre
juin 2007 et janvier 2008. Les participants se répartissaient entre
189 omnipraticiens (OP) et 139 spécialistes (anesthésistes, neurologues,
physiatres, psychiatres et rhumatologues) répartis un peu partout au
Canada. Dix-huit patients s'ajoutaient aux participants, pour enrichir la
portée des résultats.
RÉSULTATS : Les OP ont déclaré des connaissances et des compétences
insuffisantes pour diagnostiquer la fibromyalgie, et ils ne pensaient pas tous
qu'il s'agissait d'une maladie diagnosticable (moyenne de 3,74/5). Ainsi,
$23 \%$ des OP et $12 \%$ des spécialistes qualifiaient les patients atteints de
fibromyalgie de simulateurs. Ils ont également déclaré un manque de
connaissances et de compétences pour traiter la fibromyalgie (moyenne de
$2,73 / 5$ ), y compris la douleur, les troubles du sommeil et les troubles des
humeurs liés à la maladie (moyenne de 3,32/5). Les spécialistes partageaient
ces difficultés, mais à un moindre degré- " Nous ne sommes pas formés
pour traiter la détresse et la souffrance » (spécialiste). Les obstacles liés aux
attitudes étaient axés sur la frustration (moyenne de 3,91/5) et le profilage
négatif des patients atteints de fibromyalgie (moyenne de $3,06 / 5$ et
$1,99 / 5$ ). CONCLUSIONS : Les résultats ont révélé la présence d'obstacles liés à l'attitude et à la confiance chez les OP à l'égard des soins aux patients ayant une fibromyalgie. Puisque les soins des patients atteints de fibromyalgie sont en voie d'être transférés à la pratique générale, il faut transmettre ces compétences fondamentales afin de s'assurer que tous les patients reçoivent la qualité de soins nécessaires pour prendre en charge leur maladie et habiliter les médecins à être plus efficaces sur le plan professionnel. Comme l'a déclaré un patient : "Pourquoi sommes-nous pénalisés parce que nous avons cette incapacité ? »

experience moderate to severe levels of diffuse and chronic pain that may stem from a variety of sources (2). No underlying, measurable, pathophysiological abnormalities have been identified despite numerous studies examining the etiology of the illness (6). Emotional, psychological and socioeconomic components further complicate diagnosis (2), as does the similarity in symptoms to those of hypothyroidism, multiple sclerosis, myasthenia gravis, rheumatoid arthritis and systemic lupus erythematosus $(2,5)$ - all of which may contribute to misdiagnosis. Finally, the disease is associated with comorbidities such as sleep disturbance (7), depression (8), cognition dysfunction (9) and sexual dysfunction (10). Medically

${ }^{1}$ Performance Optimization Solutions, AXDEV Group Inc, Brossard, Quebec; ${ }^{2}$ Private practice, Toronto, Ontario; ${ }^{3}$ Service de Rhumatologie,

Centre Hospitalier Universitaire de Sherbrooke, Sherbrooke; ${ }^{4}$ Pain $\mathcal{E}$ Inflammation, Pfizer Canada Inc, Kirkland, Quebec

Correspondence and reprints: Dr Sean M Hayes, AXDEV Group Inc, 8 Place du Commerce, Suite 210, Brossard, Quebec J4W 3H2.

Telephone 450-465-2011, fax 450-465-1155, e-mail hayess@axdevgroup.com 
unexplained physical symptoms remain incompatible with medical thinking, with its emphasis on measurable facts, despite the fact that they are associated with high levels of morbidity and social costs (11). Consequently, many patients are left with inadequate treatment for their physical symptoms.

Compounding physical symptoms is the emotional distress experienced by patients, which is often overlooked by physicians (11). Patients experience concern that they may not recover or may deteriorate further. Even though the illness may be blurry to the eyes of many physicians, the pain is very real to the patient.

Ongoing research using advanced imaging techniques has identified changes in brain activity (12) in blood flow in singlephoton emission computed tomography and functional magnetic resonance imaging studies (13-15), and in altered responses to stimuli of varying intensities, both painful and painless. Evidence is mounting that fibromyalgia involves differences in the processing of pain (16-18), particularly in the processing of sensory input and painful stimuli $(19,20)$. A genetic basis for the syndrome has also been explored (21). However, no underlying measurable or pathophysiological causes have been confirmed (6), rendering the condition incompatible with medical/scientific models that emphasize measurable criteria (11). Psychological components, mood disorders and socioeconomic components further complicate diagnosis (2), and may be misunderstood by physicians $(11,22)$. Debate continues among physicians regarding whether fibromyalgia is a credible diagnosis at all (23-25), ranking among the lowest in credibility of conditions in a survey of physicians and medical students (26).

With no clear standardized explanation or cure for fibromyalgia, and unsupportive attitudes of their physicians, patients are at risk for descent into a 'culture of fibromyalgia' (27), which can become a self-fulfilling prophecy in which patients wrongfully believe that there is no cure and, therefore, engage in counterproductive behaviours such as developing sedentary patterns to prevent increased pain and seeking disability benefits. This pattern of behaviour generates antipathy toward patients who are seen as unwilling to help themselves, culminating in an attitude termed 'fibroism' $(26,28)$. This is further exacerbated by the combination of the high proportion of women diagnosed with fibromyalgia and increased sensitivity of women to pain (29), which contribute to fibromyalgia patients being labelled based on stereotypes of women's suffering $(27,30)$. In turn, patients become resentful toward the physician, who may be perceived as unsympathetic or as belittling their experience of pain as psychological and of less importance (31). This can create a downward spiral of frustration, in which patients and physicians are unable to collaborate together effectively.

To gain a better understanding of the nature of the patient-provider relationship in fibromyalgia, and the underlying knowledge and attitudinal challenges, a national, multidisciplinary needs assessment was undertaken with the following research objectives:

1. To assess challenges in providing care to people with fibromyalgia, focusing on knowledge, skill, attitudes and clinical practice behaviours of practising Canadian physicians in providing care for people with fibromyalgia;
2. To assess targeted health care providers' issues, challenges and perspectives regarding patient profiles, prioritization and needs that affect health care providers' effectiveness in this therapeutic domain; and

3. To identify and determine educational needs and inform the development of educational and performance improvement initiatives in providing care for people with fibromylagia.

\section{METHODS}

A mixed-methods approach was used, including both qualitative (discussion groups and semistructured interviews) and quantitative (online survey) data collection techniques to enhance trustworthiness of findings $(32,33)$. A triangulated research design combined data sources and collection methods to examine the same phenomena (33-35), strengthening the validity of the evidence.

The design of discussion group guides and semistructured individual interview guides was based on a comprehensive literature review. Discussion groups lasted half a day and individual interviews lasted approximately $60 \mathrm{~min}$. Data were audiorecorded and transcribed.

A quantitative survey was developed based on substantive findings of the qualitative study phase. Items were rated on a five-point Likert scale.

Discussion groups and interviews were conducted from June to September 2007; survey data were collected from September 2007 to January 2008. Ethical approval (Institutional Review Board Services, Aurora, Ontario) was obtained.

\section{Subjects}

Participants included 189 general practitioners (GPs) (family physicians and GPs), 139 specialists (rheumatologists, psychiatrists, neurologists, physiatrists and anesthesiologists), two nurses and 18 patients (Table 1). Purposive sampling ensured that the sample was representative of the target audience of practising Canadian physicians $(33,35)$.

Physician participants in all groups were identified from lists and approached via fax, e-mail and online invitation. Those who expressed interest in participating were screened based on inclusion criteria assessing the percentage of patients with fibromyalgia (pain experts, greater than $10 \%$; nonpain experts, greater than 5\%; and GPs, greater than 1\%), and distributions of years in practice, practice location and sex. Patients were approached via brochures in participating physicians' offices, newspaper advertisements and patient advocate groups. Inclusion criteria were based on diagnosis (longer than six months) and having been seen by a health care professional for fibromyalgia at least twice in the previous year. Recruitment for the two phases was conducted separately. Participants were recruited for the first phase, qualitative data collection and analysis of the first phase was completed, and then recruitment was conducted for the second phase. Appropriate financial compensation was provided for participation.

Thirty-two participants took part in the qualitative phase and 296 took part in the quantitative online survey (Table 1). Practices were generally located in private clinics in urban centres distributed across Canada but concentrated in Quebec and Ontario (generalists, 53\%; and specialists, 61\%). Eightyone per cent of generalists practised in private clinics and $3 \%$ practised in hospitals; $49 \%$ of specialists practised in private 
clinics and $36 \%$ practised in hospitals. Fibromyalgia was well represented in participants' practices: $75 \%$ of survey participants saw 11 or more fibromyalgia patients in their practices.

Patient participants were predominantly women living in urban centres, concentrated between the ages of 41 to 60 years, with $22 \%$ diagnosed with fibromyalgia for fewer than six years and $66 \%$ diagnosed between six and 15 years previously. Sixtyone per cent were followed predominantly by their family physician for their fibromyalgia.

\section{Analysis}

Qualitative analysis: Coding of qualitative data was based on grounded theory, in which concepts are drawn from the data (36). Initially, open coding was performed (37), reviewing the data in detail based on the conceptual framework and research questions identified above. Coders were experienced qualitative researchers, including coauthors SH, GM, KC and SM.

Coding categories were then grouped into related themes (eg, Knowledge of diagnostic criteria; Attitude toward patients with fibromyalgia) and subthemes (eg, Knowledge of diagnostic criteria - challenges in knowledge of criteria, and challenges in application of criteria; Attitude toward patients with fibromyalgia - frustration with inability to engage patients, and negative profiling). Themes were validated among coders and discrepancies were resolved through discussions until concordance was achieved.

Quantitative analysis: Quantitative data were analyzed using nonparametric testing (Mann-Whitney) (SPSS 12.0 software, SPSS Inc, USA).

\section{RESULTS}

Challenges in knowledge and skill in assessing and managing the constellation of symptoms and comorbidities associated with fibromyalgia are detailed below, followed by characterization of the attitudes toward fibromyalgia and patients with fibromyalgia.

\section{Definition and diagnosis}

Attitudinal issues began with physicians questioning the validity of fibromyalgia itself and the effect of these doubts on interactions with patients, as exemplified by the following GP:

I'm not convinced, how can I convince somebody?

That's my problem with fibromyalgia, I'm not convinced at all. (GP)

Participants further commented on the lack of clarity of the definition of fibromyalgia:

It's a fuzzy concept. It's a fuzzy clinical situation. It's fuzzy. (Specialist)

A total of $41 \%$ of GPs and $37 \%$ of specialists reported unclear diagnostic criteria as a barrier in their identification of fibromyalgia (Table 2). A total of $35 \%$ of GPs lacked confidence in using the American College of Rheumatology (ACR) criteria; significantly fewer specialists did so (26\%).

And it does have some criteria, and it's complex, and we definitely don't understand it as well as we need to. (GP)
TABLE 1

Sample distribution

\begin{tabular}{|c|c|c|c|}
\hline Physicians & n (\%) & Patients & n (\%) \\
\hline Specialty & & Main health care provider & \\
\hline $\begin{array}{l}\text { Family physicians/ } \\
\text { general practitioners }\end{array}$ & $189(58)$ & $\begin{array}{l}\text { Family physician/ } \\
\text { general practitioner }\end{array}$ & $11(61)$ \\
\hline Rheumatologists & $39(12)$ & Specialist & $6(33)$ \\
\hline Psychiatrists & $31(9)$ & Other & $1(6)$ \\
\hline Neurologists & $26(8)$ & Sex & \\
\hline Physiatrists & $23(7)$ & Male & $3(17)$ \\
\hline Anesthesiologists & $18(6)$ & Female & $15(83)$ \\
\hline Other & $2(1)$ & Location & \\
\hline Sex & & Urban $(>500,000)$ & $13(72)$ \\
\hline Male & 235 (73) & Suburban $(100,000-$ & $4(22)$ \\
\hline Female & $87(27)$ & $500,000)$ & \\
\hline Main work setting & & Rural $(<100,000)$ & $1(6)$ \\
\hline Private clinic & $221(69)$ & Age, years & \\
\hline Hospital & $56(18)$ & $\leq 40$ & $2(11)$ \\
\hline Other settings & $43(13)$ & $41-50$ & $5(28)$ \\
\hline Location of main practice & & $51-60$ & $9(50)$ \\
\hline Urban $(>500,000)$ & $231(72)$ & $\geq 61$ & $2(11)$ \\
\hline Suburban $(100,000-$ & $41(13)$ & Years since diagnosis & \\
\hline 500,000$)$ & & $<6$ & $4(22)$ \\
\hline Rural $(<100,000)$ & $49(15)$ & $6-10$ & $8(44)$ \\
\hline Region & & $11-15$ & $4(22)$ \\
\hline Atlantic & $24(8)$ & $\geq 16$ & $2(11)$ \\
\hline Quebec & $54(18)$ & & \\
\hline Ontario & $132(44)$ & & \\
\hline Prairies & $60(20)$ & & \\
\hline British Columbia & 33 (11) & & \\
\hline \multicolumn{4}{|c|}{$\begin{array}{l}\text { Number of patients with fibromyalgia } \\
\text { (survey) }\end{array}$} \\
\hline$\leq 10$ & $77(25)$ & & \\
\hline $11-25$ & $70(22)$ & & \\
\hline $26-50$ & $87(28)$ & & \\
\hline $51-75$ & $14(4)$ & & \\
\hline $76-100$ & $25(8)$ & & \\
\hline 101-199 & $18(6)$ & & \\
\hline$\geq 200$ & $22(7)$ & & \\
\hline
\end{tabular}

A total of $36 \%$ of GPs expressed doubts about their ability to diagnose fibromyalgia; significantly fewer specialists did so (25\%) (Table 2). Two-thirds of participants (63\% of GPs and $66 \%$ of specialists) characterized fibromyalgia as diagnosable. However, many commented on the subjectivity of the assessment:

It's very subjective, so this is just based on a faith in patients saying [...] "It hurts; my [...] is sore". But you don't have a measure of how much you can press the [tender] point. (GP)

\section{Treatment and management}

Participants reported lack of knowledge of treatment options (30\% of GPs and $24 \%$ of specialists):

There's a few drugs that have been tried and nothing seems to really work too well and that's it. (GP)

Patients echoed this uncertainty on the part of their physicians: 
TABLE 2

Ratings of challenges and barriers in diagnosing, treating and relating to patients with fibromyalgia: Online survey responses

\begin{tabular}{|c|c|c|c|c|c|}
\hline Diagnosis & Total $(n=328)$ & GPs (n=189) & Specialists $(n=139)$ & $\mathbf{Z}$ & $\mathbf{P}$ \\
\hline \multicolumn{6}{|c|}{ Agreement with statements: 1 = completely disagree, $5=$ completely agree } \\
\hline Use of ACR criteria in practice & $3.59 \pm 1.03$ & $3.65 \pm 1.02$ & $3.51 \pm 1.05$ & -1.05 & 0.29 \\
\hline Fibromyalgia is diagnosable & $3.74 \pm 0.93$ & $3.73 \pm 0.90$ & $3.75 \pm 0.98$ & -0.39 & 0.70 \\
\hline \multicolumn{6}{|l|}{ Statement represents a barrier: $1=$ not at all, $5=$ to a great extent } \\
\hline Unclear diagnostic criteria/guidelines & $3.08 \pm 1.11$ & $3.16 \pm 1.11$ & $2.97 \pm 1.093$ & -1.18 & 0.24 \\
\hline Confidence in using ACR criteria in diagnosis & $2.83 \pm 1.09$ & $2.97 \pm 1.06$ & $2.64 \pm 1.10$ & -2.50 & 0.01 \\
\hline Ability to diagnose fibromyalgia & $2.91 \pm 1.09$ & $3.08 \pm 1.05$ & $2.66 \pm 1.10$ & -3.11 & 0.002 \\
\hline \multicolumn{6}{|l|}{ Treatment } \\
\hline \multicolumn{6}{|l|}{ Statement represents a barrier: $1=$ not at all, $5=$ to a great extent } \\
\hline Knowledge of treatments & $2.73 \pm 1.05$ & $2.87 \pm 1.03$ & $2.52 \pm 1.04$ & -2.80 & 0.01 \\
\hline Knowledge of monitoring treatment response & $3.07 \pm 1.06$ & $3.21 \pm 1.10$ & $2.87 \pm 0.99$ & -2.77 & 0.01 \\
\hline Knowledge of monitoring tools & $3.45 \pm 0.95$ & $3.59 \pm 0.89$ & $3.23 \pm 1.00$ & -3.32 & 0.00 \\
\hline Ability to evaluate response to treatment & $3.01 \pm 1.01$ & $3.12 \pm 1.02$ & $2.85 \pm 0.98$ & -2.24 & 0.03 \\
\hline \multicolumn{6}{|l|}{ Therapeutic relationship } \\
\hline \multicolumn{6}{|c|}{ Agreement with statements: $1=$ completely disagree, $5=$ completely agree } \\
\hline Fibromyalgia patients are not proactive & $3.06 \pm 0.92$ & $3.04 \pm 0.93$ & $3.09 \pm 0.91$ & -0.75 & 0.75 \\
\hline Fibromyalgia patients are malingerers & $1.99 \pm 1.06$ & $2.13 \pm 1.11$ & $1.79 \pm 0.93$ & -2.52 & 0.01 \\
\hline Fibromyalgia patients are time consuming, frustrating & $3.91 \pm 0.90$ & $4.02 \pm 0.86$ & $3.75 \pm 0.92$ & -2.54 & 0.01 \\
\hline \multicolumn{6}{|l|}{ Statement represents a barrier: $1=$ not at all, $5=$ to a great extent } \\
\hline Ability to provide psychological support & $3.32 \pm 1.23$ & $3.35 \pm 1.20$ & $3.28 \pm 1.28$ & -0.37 & 0.71 \\
\hline Ability to establish a positive working relationship & $2.88 \pm 1.15$ & $2.92 \pm 1.159$ & $2.82 \pm 1.15$ & -0.75 & 0.46 \\
\hline Ability to manage patients' expectations & $3.52 \pm 1.02$ & $3.57 \pm 1.020$ & $3.45 \pm 1.03$ & -1.07 & 0.28 \\
\hline Ability to establish successful communication and dialogue & $2.72 \pm 1.10$ & $2.71 \pm 1.087$ & $2.73 \pm 1.11$ & -0.21 & 0.836 \\
\hline Ability to quantify disability for insurance purposes & $3.85 \pm 1.20$ & $4.02 \pm 1.165$ & $3.59 \pm 1.21$ & -3.28 & 0.001 \\
\hline Knowledge and skill in completing disability applications & $3.53 \pm 1.22$ & $3.78 \pm 1.147$ & $2.85 \pm 1.23$ & -4.36 & 0.00 \\
\hline
\end{tabular}

Data presented as mean \pm SD. Items were rated on five-point Likert scales indicating level of agreement with the statement presented or extent to which the statement provided describes a barrier to practice. Results are presented for the entire sample as well as for general practitioners (GPs) and specialists separately. Nonparametric testing (Mann-Whitney) was performed. ACR American College of Rheumatology

They all prescribe different medication because they don't really know what it is. The medication they give you is harmful to begin with, they make you worse than you are. (Patient)

Use of opiates was identified as a component of the management of fibromyalgia pain, with concern expressed about side effects and dependency on narcotics:

You're getting yourself into a vortex of side effects and perhaps drug dependencies and drug overuse and misuse and abuse. (GP)

Physician participants generally did not turn to nonpharmaceutical interventions, expressing frustration with lack of patient adherence to programs:

They say they want to get better, but they don't help themselves get better. (Specialist)

Participants reported that they believed they could no longer help these patients:

They have a chronic illness, chronic pain, and I see them when something new or unmanageable is going on. There's no point. There's nothing more I can offer them. (Specialist)

Knowledge of monitoring tools emerged as an important challenge, as reported by $65 \%$ of GPs and $43 \%$ of specialists. Ratings of challenges in the management of fibromyalgia were significantly higher for GPs compared with specialists (Table 2). The ambiguity of fibromyalgia and lack of familiarity with emotional issues were characterized:

We are used to clinical markers of disease in our work, usually. And here the markers are distress and suffering, and we are not trained to treat distress and suffering. (Specialist)

One-half of participants (51\% of GPs and $50 \%$ of specialists) identified their inability to offer psychological support to patients as a barrier to care (Table 2). Overall, $66 \%$ of GPs and $53 \%$ of specialists reported that they should be doing more to help their patients with fibromyalgia. The patients agreed:

What can health professionals do for me? Real short.

Don't tell me to cope. Tell me how to cope. (Patient)

I don't think we're being followed - I think we're following them! (Patient)

However, $23 \%$ of GPs and $12 \%$ of specialists agreed with a statement that fibromyalgia patients are malingerers, with GPs agreeing significantly more strongly (Table 2). Seventy-six per cent of GPs and 64\% of specialists (significantly fewer; Table 2) described fibromyalgia patients as time consuming and frustrating. These patients stated the following:

I think bottom line is no one really wants to look at it. It's a lot of work, it's very unrewarding, you don't really 
see any concrete results. It's always like a constant decline, so it becomes very unsatisfying as a result. (GP)

A proportion of fibromyalgia patients apply for and receive disability benefits, with the insurance application process creating additional barriers for participants (66\% to $72 \%$ of GPs and $42 \%$ to $61 \%$ of specialists; Table 2 ). This process was further characterized as having a negative impact on successful therapeutic outcomes:

If the patient is in present litigation and seeking disability - you cannot get better if you have to prove that you are ill. (Specialist)

Patients shared this frustration with their own ongoing disability:

I should be healthy, I should be working [...] they need to help you out, make you better, not just say, 'This is it, you're stuck with this for your life.' (Patient)

Participants expressed understanding that the patients' experience of fibromyalgia illness was difficult and affected their illness behaviours:

You immediately know they have fibromyalgia, often, even before they say anything, just from the way they're behaving, and their personality. I find the fibromyalgia patients $[. .$.$] tend to be under a lot of stress, they tend to$ cope poorly, they have a lot of depressive [...] It just shows. (Specialist)

Others held the patients accountable for their ongoing symptoms and pain, and need for support, interventions and relief.

There are patients who really adopt their illness and they want to live with it, they want to keep it up. (Specialist)

Patients become aware of this attitude:

I've seen maybe six rheumatologists [...] They don't want to be bothered with you. (Patient)

Physicians often described the therapeutic relationship as unidirectional, with patients expected to follow physicians' instructions:

Define the limits - that's so important. I like that term. That we can't cure them; that we don't fall in with them; that they don't direct [...] what type of pain pills they need or what type of treatment. (GP)

Patients perceived the medical expectation that they be 'good' patients and reacted to this expectation:

We should be saving that energy to do positive things, but right now [...] you have to defend. Why should we have to do it? Like why are we being penalized for having this disability? (Patient)

It's a no-win situation with doctors. (Patient)

Identifying patients who would be 'worth it' was identified as a need by participants:
Is there a screening method, a psychological profiling of sorts that say: this is a patient worth working with and these are patients that [aren't]? (GP)

In summary, fibromyalgia is characterized by undefined pathophysiology, uncertainty about diagnostic criteria, lack of knowledge regarding effective and safe treatments, and the need for a broad range of support and intervention that physicians are ill equipped to provide. These factors combine to create a climate of mismatched perceptions and unmet needs on the parts of both patients and physicians in the treatment of fibromyalgia.

\section{DISCUSSION}

Findings of this mixed-method needs assessment identified gaps in knowledge and skill in diagnosing fibromyalgia. Onequarter of GPs and one-tenth of specialists described fibromyalgia patients as malingerers. Some participant GPs believed that it is not a diagnosable condition, in contrast with those who expressed knowledge and skill in diagnosing the disorder. As well, there were reports of lack of knowledge and skill in treating fibromyalgia, including pain and other clinical features of the condition. These challenges were also identified in the group of specialists, although to a lesser degree. This is consistent with findings of previous research describing diagnostic and treatment gaps in care of fibromyalgia patients $(1,38,39)$ and identifying attitudes of frustration toward the disease and its sufferers. Of particular concern is the discussion by some participants of the use of opiates in managing pain. Research evidence suggests that opiates are of limited use for fibromyalgia patients (40-42), yet findings indicate that this questionable management strategy is being used despite evidence to the contrary.

Attitudes expressed in the current study described interplay of these challenges and attitudes in which physicians expressed gaps in knowledge of how to diagnose and manage fibromyalgia. There was some further expression of uncertainty that fibromyalgia exists and blaming of patients for malingering. When confronted with patients who experienced symptoms that were nebulous and difficult to quantify, physicians themselves experienced frustration with patients' ongoing demands for relief and support, partly due to their perceived lack of skills and knowledge regarding therapeutic interventions to help their patients. This contributed to profiling of fibromyalgia patients (28) and 'fibroism' (26). Patients reported sensing this antipathy, contributing to a spiral of mutual impatience and intolerance. Patients described needing not only medical treatment but also psychosocial support that they do not receive.

Ability to communicate with patients and to advocate on their behalf is within the Communicator and Health Advocate roles of the CanMEDS (43) framework of the Royal College of Physicians and Surgeons of Canada. These abilities are fundamental to an effective therapeutic relationship. The importance of communication and psychosocial skills is highlighted in a condition such as fibromyalgia, in which pathophysiology, diagnostic testing and treatment are imprecise. As care of fibromyalgia falls increasingly within the mandate of GPs (44), the need for skill in relational and communication abilities grows, as does skill in providing not only physical but also emotional support. The collaborative doctor-patient approach has been identified as critical in managing 
fibromyalgia (11), centring around problem identification and patients' needs. Communication skills (45) are indispensable in this process (43).

The identification of attitudinal and communication challenges in the management of fibromyalgia suggests targets for performance improvement initiatives. Exposure of health care providers to the patients' experiences and goals in managing fibromyalgia would provide the basis for common understanding of patient behaviours. GPs and specialists with the necessary knowledge, skill and attitudes to provide appropriate care for patients with fibromyalgia could act as role models of competence of the effectiveness of positive, supportive attitudes toward these patients. This understanding would serve to guide physicians in providing psychosocial support as well as medication and pain control.

\section{Limitations}

The results of the present study are based on self-report, which introduces the possibility of inaccuracies due to erroneous selfassessment. However, this is consistent with the objective of the research, which was to assess subjects' perceptions of gaps, barriers and attitudes. Self-evaluation has been found to be subject to inaccuracies and, therefore, may need to be supported by objective data in determining true practice gaps and areas for performance improvement (46). In the present study, triangulation of findings across focus groups, interviews and

\section{REFERENCES}

1. Annemans L, Wessely S, Spaepen E, et al. Health economic consequences related to the diagnosis of fibromyalgia syndrome. Arthritis Rheum 2008;58:895-902.

2. Wolfe F, Smythe HA, Yunus MB, et al. The American College of Rheumatology 1990 Criteria for the Classification of Fibromyalgia. Report of the Multicenter Criteria Committee. Arthritis Rheum 1990;33:160-72.

3. White K, Speechley M, Harth M, Ostby T. The London Fibromyalgia Epidemiology Study: The prevalence of fibromyalgia syndrome in London, Ontario. J Rheumatol 1999;26:1570-6.

4. McNally JD, Matheson DA, Bakowsky VS. The epidemiology of self-reported fibromyalgia in Canada. Chronic Dis Can 2006;27:9-16.

5. Jain AK, Carruthers BM. Fibromyalgia syndrome: Canadian clinical working case definition, diagnostic and treatment protocols a consensus document. J Musculoskeletal Pain 2003;11:3-107.

6. Carrette S. Fibromyalgia 20 years later: What have we really accomplished? J Rheumatol 1995;22:590-4.

7. Moldofsky $\mathrm{H}$. The significance of dysfunctions of the sleeping/ waking brain to the pathogenesis and treatment of fibromyalgia syndrome. Rheum Dis Clin North Am 2009;35:275-83.

8. Goldenberg DL. The interface of pain and mood disturbances in the rheumatic diseases. Semin Arthritis Rheum 2010;40:15-31.

9. Glass JM. Fibromyalgia and cognition. J Clin Psychiatry 2008;69(Suppl 2):20-4.

10. Orellana C, Gratacós J, Galisteo C, Larrosa M. Sexual dysfunction in patients with fibromyalgia. Curr Rheumatol Rep 2009;11:437-42.

11. Richardson RD, Engel CC Jr. Evaluation and management of medically unexplained physical symptoms. Neurologist 2004:10:18-30.

12. Demitrack MA, Crofford LJ. Evidence for and pathophysiologic implications of hypothalamic-pituitary-adrenal axis dysregulation in fibromyalgia and chronic fatigue syndrome. Ann N Y Acad Sci 1998;840:684-97.

13. Kwiatek R, Barnden L, Tedman R, et al. Regional cerebral blood flow in fibromyalgia: Single-photon-emission computed tomography evidence of reduction in the pontine tegmentum and thalami. Arthritis Rheum 2000;43:2823-33.

14. Mountz JM, Bradley LA, Modell JG, et al. Fibromyalgia in women. Abnormalities in regional cerebral blood flow in the thalamus and survey data was used to strengthen the trustworthiness of the findings. The physician sample was predominantly male, which may have affected the findings related to fibromyalgia, with its sex-based influences. It should also be emphasized that the specialist group was presented as a single group in the present analysis. In fact, it is a heterogeneous group.

\section{CONCLUSIONS}

The findings of the present mixed-methods study have identified attitudinal and confidence challenges in the care of fibromyalgia patients, particularly in diagnosis, treatment, patient communication and the therapeutic relationship of GPs. As care of fibromyalgia patients moves to general practices, these fundamental competencies of the CanMEDS framework must be addressed to ensure that all patients receive the quality of care necessary to manage their disease. Performance improvement initiatives should be tailored to underlying attitudinal and confidence issues related to care of patients with fibromyalgia and their impact on the therapeutic relationship.

ACKNOWLEDGEMENTS: The authors express their appreciation for the contributions of the physicians who participated in this study. This study was funded by an unrestricted grant from Pfizer Canada Inc. caudate nucleus are associated with low pain thresholds. Arthritis Rheum 1995;38:926.

15. Iadarola MJ, Max MB, Berman KF. Unilateral decrease in thalamic activity observed in positron emission tomography in patients with chronic neuropathic pain. Pain 1995;63:55-64.

16. Guedj E, Cammilleri S, Niboyet J, et al. Clinical correlate of brain SPECT perfusion abnormalities in fibromyalgia. J Nucl Med 2008:49:1798-803.

17. Huynh CN, Yanni LM, Morgan LA. Key practice points in the management of fibromyalgia. Am Fam Physician 2007;76:195-6,202.

18. Julien N. Widespread pain in fibromyalgia is related to a deficit of endogenous pain inhibition. Pain 2005;114:295-302.

19. Gracely RH, Petzke F, Wolf JM, Clauw DJ. Functional magnetic resonance imaging of augmented pain processing in fibromyalgia. Arthritis Rheum 2002;46:1333-43.

20. Cook DB, Lange G, Ciccone DS, et al. Functional imaging of pain in patients with primary fibromyalgia. J Rheumatol 2004;31:364-78.

21. Ablin J, Neumann L, Buskila D. Pathogenesis of fibromyalgia a review. Joint Bone Spine 2008;75:273-9.

22. Greenhalgh S. Under the Medical Gaze: Facts and Fictions of Chronic Pain. Berkeley: University of California Press, 2001.

23. Hazemeijer I, Rasker J. Fibromyalgia and the therapeutic domain. A philosophical study on the origins of fibromyalgia in a specific social setting. Rheumatology 2003;42:507-15.

24. Ehrlich G. Pain is real: Fibromyalgia isn't. J Rheumatol 2003;30:1666-7.

25. Sipkoff M. Fibromyalgia coverage uneven despite recent drug approvals. Manag Care 2008;17:9-10.

26. Album D, Westin S. Do diseases have a prestige hierarchy? A survey among physicians and medical students. Soc Sci Med 2008;66:182-8.

27. Alghalyini B, Oldfield M. That sinking feeling: A patient-doctor dialogue about rescuing patients from fibromyalgia culture. Can Fam Physician 2008;54:1576-7.

28. Camerlain M, Myhal G. Are we profiling patients with fibromyalgia? Pain Res Manage 2009;14:238.

29. Fillingim RB, King CD, Ribeiro-Dasilva MC, Rahim-Williams B, Riley JL III. Sex, gender, and pain: A review of recent clinical and experimental findings. J Pain 2009;10:447-85. 
30. Barker KK. The Fibromyalgia Story: Medical Authority and Women's Worlds of Pain. Philadelphia: Temple University Press, 2005.

31. Raymond MC, Brown JB. Experience of fibromyalgia: Qualitative study. Can Fam Physician 2000;46:1100-6.

32. Chatterji M. Evidence on "what works": An argument for extended-term mixed method (ETMM) evaluation designs. Educ Researcher 2005;34:14-24.

33. Johnson RB, Onwuegbuzie AJ. Mixed methods research: A research paradigm whose time has come. Educ Researcher 2004;33:14-26.

34. Denzin NK, Lincoln YS, eds. Handbook of Qualitative Research, 2nd edn. Thousand Oaks: Sage Publications, 2000.

35. Creswell JW. Research Design: Qualitative, Quantitative, and Mixed Approaches. Thousand Oaks: Sage Publications, 2003.

36. Strauss A, Corbin J. Basics of Qualitative Research: Grounded Theory Procedures and Techniques. Newbury Park: Sage Publications, 1990.

37. Neuendorf KA. The Content Analysis Guidebook. Thousand Oaks: Sage Publications, 2002.

38. Lynch ME. Do we care about people with chronic pain? Pain Res Manage 2008;13:463.

39. McAllister J. Primary care: MD's empathy may affect patient outcomes. Medical Post 2008;44:15.
40. Sörensen J, Bengtsson A, Bäckman E, Henriksson KG,

Bengtsson M. Pain analysis in patients with fibromyalgia. Effects of intravenous morphine, lidocaine, and ketamine. Scand J Rheumatol 1995;24:360-5.

41. Sörensen J, Bengtsson A, Ahlner J, Henriksson KG, Ekselius L, Bengtsson M. Fibromyalgia - are there different mechanisms in the processing of pain? A double blind crossover comparison of analgesic drugs. J Rheumatol 1997;24:1615-21.

42. Arnold LM. Biology and therapy of fibromyalgia. New therapies in fibromyalgia. Arthritis Res Ther 2006;8:212.

43. Frank JR, Jabbour M, Fréchette D, et al, eds. Report of the CanMEDS Phase IV Working Groups. Ottawa: The Royal College of Physicians and Surgeons of Canada, March 2005. <http://rcpsc. medical.org/canmeds/index.php> (Accessed on November 22, 2010).

44. Perrot S, Dickenson AH, Bennett RM. Fibromyalgia: Harmonizing science with clinical practice considerations. Pain Pract 2008;8:177-89.

45. van den Brink-Muinen A, van Dulmen AM, Jung HP, Bensing JM. Do our talks with patients meet their expectations? J Fam Pract 2007;56:559-68.

46. Davis DA, Mazmanian PE, Fordis M, Van Harrison R, Thorpe KE, Perrier L. Accuracy of physician self-assessment compared with observed measures of competence: A systematic review. JAMA 2006;296:1094-102. 


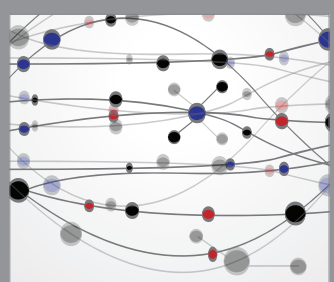

The Scientific World Journal
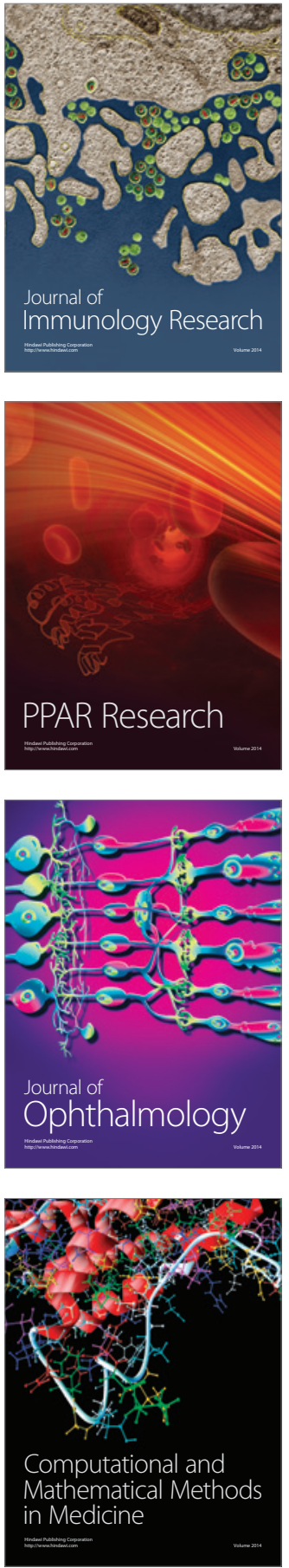

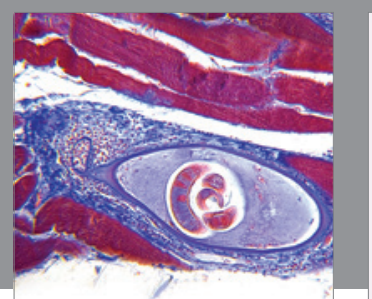

Gastroenterology Research and Practice

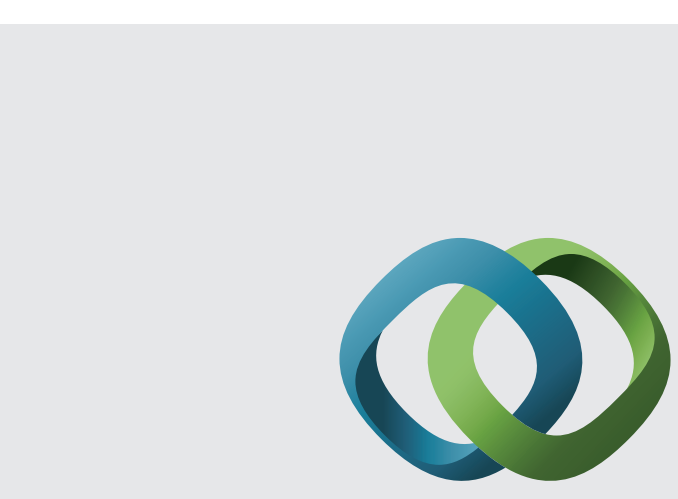

\section{Hindawi}

Submit your manuscripts at

http://www.hindawi.com
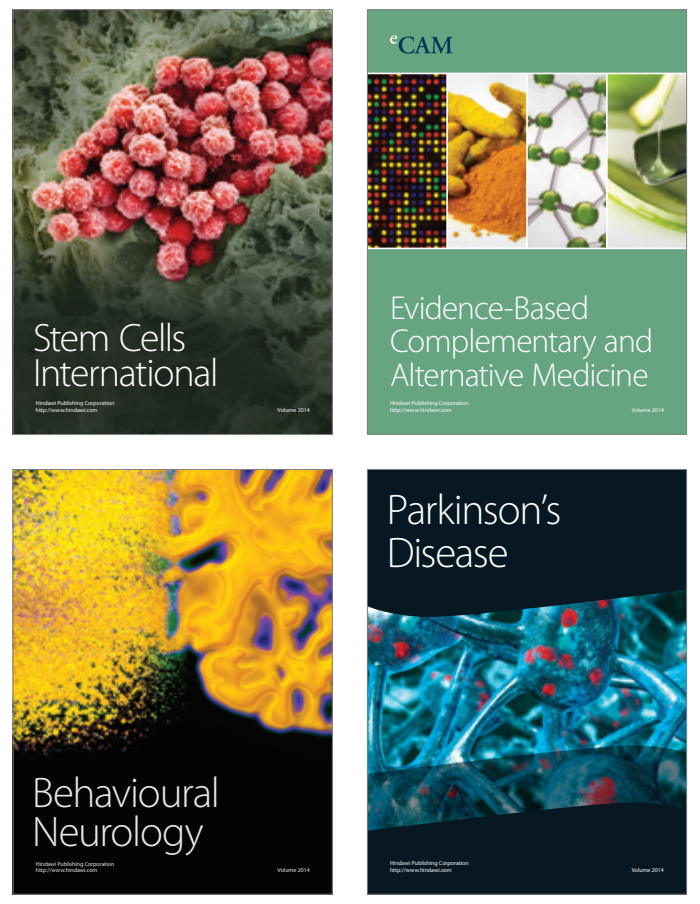
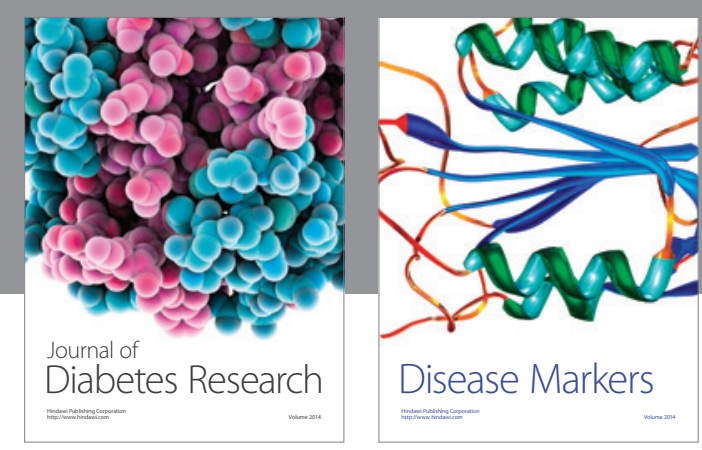

Disease Markers
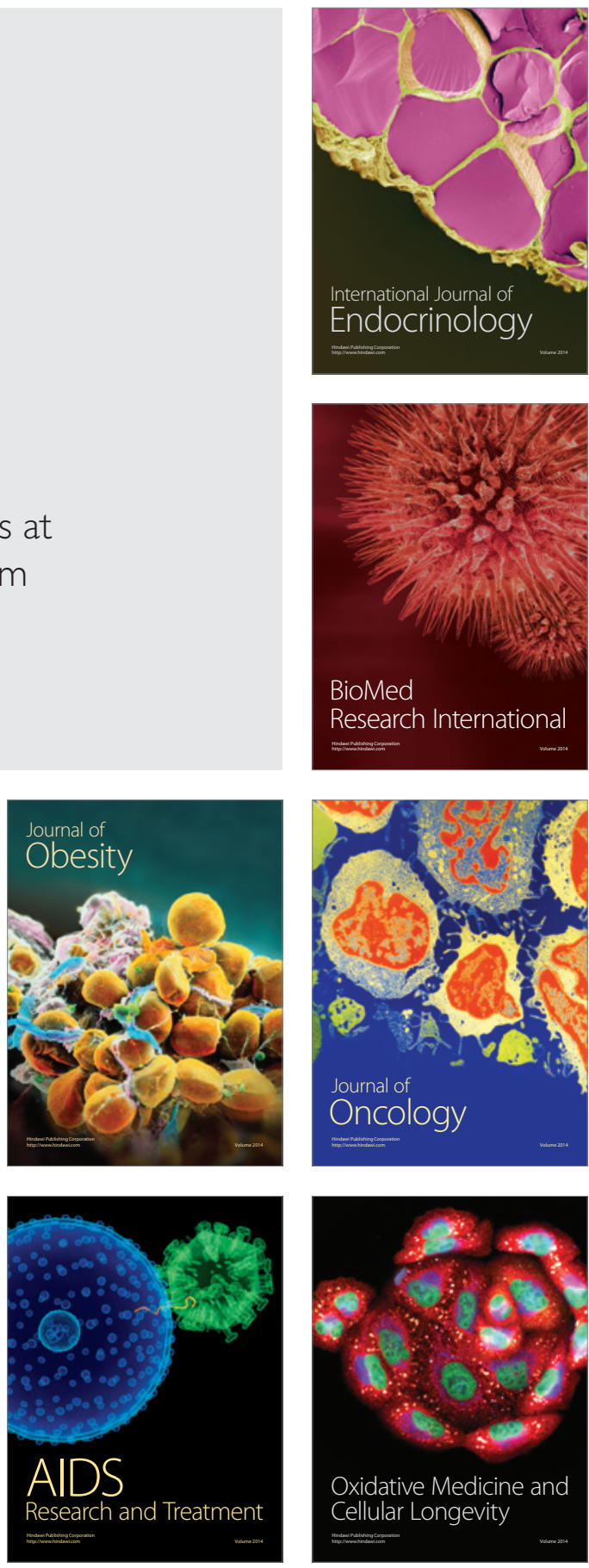